\title{
PENDIDIKAN \\ DALAM PERSPEKTIF ISLAM
}

\author{
Asrori \\ Sekolah Tinggi Agama Islam Jakarta
}

\section{Abstract:}

Sinceits birth, Islam is a religion thathas concernedoneducation. The first verse of Al-Qur'anfor the Prophet Muhammad and the prophetic mission of Muhammad show this concern. The condition of ignorance that dominated the Arab society in the past was tried to be changed by Islam. The Islamic education is often called tarbiyah and ta'lim al-tarbiyah which means education that includes aspects of science and morality. Therefore, Islamic education is to cultivate humans' minds and to regulate humans' characters and attitudes based on the Islamic teachings. Meanwhile al-ta'lim in Islamic education means teaching, which only gives knowledge to the students. According to Islamic teachings, humans have two potentials (evil and piety). The teachings of Islam acknowledge the differences of people's talents but the differences do not mean that they cannot be formed at all. In order to achieve the goals well, education needs to be adapted with the development of the students.

Keywords: Islam, education, tarbiyah, and ta'lim. 


\section{Abstrak:}

Sejak kemunculannya, Islam adalah agama yang konsen dengan pendidikan. Ayatyangpertamaturundanmisikenabian Muhammad menunjukkan hal tersebut. Kondisi kebodohan yang mendominasi masyarakat Arab pada waktu itu berusaha untuk dirubah oleh Islam. Pendidikan Islam sering diistilahkan dengan tarbiyah dan ta'lim al-tarbiyah yang berarti pendidikan yang mencakup aspek ilmu dan akhlak. Oleh karena itu, pendidikan menurut Islam ialah menumbuhkan pikiran manusia, serta mengatur akhlak dan perangainya berdasarkan ajaran Islam. Sedangkan al-ta'lim dalam dunia pendidikan berarti pengajaran, yang hanya memberikan ilmu semata kepada anak didik. Menurut ajaran Islam, manusia itu mempunyai dua potensi (jahat dan takwa atau positif). Ajaran Islam mengakuiadanya perbedaan bakatpembawaan padadiriseseorang, namun perbedaan tersebut bukan berarti tidak bisa dibentuk sama sekali. Agarmencapai sasaran dan berhasil dengan baik, pendidikan perlu disesuaikan dengan perkembangan anak didik.

Kata kunci: Islam, pendidikan, tarbiyah, ta 'lim 


\section{A. PENDAHULUAN}

T slam lahir membawa revolusi pendidikan. Hal ini dapat dipahami dari ayat yang pertama turun, menurut mayoritas ¿ ulama, adalah surat al-'Alaq. Isinya mengandung perintah untuk belajar. Berdasar ayat tersebut, Rasulullah Saw mewajibkan kepada umatnya untuk menuntut ilmu:

$$
\text { طلب العلم فريضة على كل مسلم و مسلمة (رواه ابن ماجهة) }
$$

Artinya:

\section{Menuntut ilmu itu wajib bagi setiap muslim dan muslimah}

Rasulullah juga memberikan bimbingan kepada umatnya agar sukses, baik di dunia maupun di akhirat, dengan memperkaya ilmu pengetahuan, sebagaimana diungkap dalam sabdanya:

من ار اد الدنيا فعليه بالعلم و من اراد الآخرة فعليه بالعلم ومن ار اد هما فعليه بالعلم

Artinya:

Siapa ingin (bahagia di) dunia harus berilmu, siapa ingin bahagia di akhirat harus berilmu, dan siapa ingin bahagia dunia dan akhirat harus berilmu

Langkah awal perjuangan Rasulullah adalah memberantas buta huruf secara besar-besaran, karena beliau tahu benar bahwa agama tidak akan tumbuh bila umatnya bodoh. Rasulullah berhasil mengubah masyarakat arabyang semula bodoh (jahiliyah) menjadi masyarakat yang berilmu. Islam pun cepat menyebar ke pelbagi pelosok dunia, dan mewariskan berbagai budaya yang sangat tinggi dan berguna bagi umat manusia.

Sangat disayangkan, kitab-kitab warisan abad VIII sampai XIII yang berbicara sosiologi, ilmu hukum, astronomi, ilmu gizi, falsafah, pendidikan, logika, matematika, arsitektur, konstruksi, sastra, dan kedokteran tidak terjamah. Ironisnya, warisan inilah yang selanjutnya diambil dan dikembangkan oleh bangsa Eropa dan hasilnya digunakan untuk menjajah, menindas, dan memeras umat Islam. ${ }^{1}$

\footnotetext{
${ }^{1}$ M. Chabib Toha, Strategi Pendidikan Islam Menyongsong Abad XXI, (Cirebon : PanitiaSeminardalam Lokakarya NasionalPendidikan Islam, 1995), h.5
} 


\section{B. PEMBAHASAN}

\section{Pengertian Pendidikan.}

Istilah pendidikan yang sering digunakan dalam bahasa arab adalah tarbiyah dan ta'lim. Kedua istilah tersebut diambil dari kata dasar rabba dan 'allama. Dr. Ahmad Syarabashi membedakan antara ta'lim dan tarbiyah. Ta'lim adalah pengajaran dan penghimpunan informasi-informasi, biasanya dalam otak, sedangkan tarbiyah mengandung pengertian pengarahan, pendidikan, dan latihan. Ta'lim mengarahkan pertama-tama kepada pencerdasan akal, ingatan, dan hafalan, sedangkan tarbiyah pertama-tama mengarahkan kepada pendidikan jiwa, rohani, dan hati. ${ }^{2}$

Dari pengertian diatas dapat dikatakan bahwa al-ta'lim dalam dunia pendidikan berarti pengajaran, yang hanya memberikan ilmu semata kepada anak didik. Sedangkan al-tarbiyah berarti pendidikan yang mencakup aspek ilmu dan akhlak. Oleh karena itu, pendidikan menurut Islam ialah menumbuhkan pikiran manusia, serta mengatur akhlak dan perangainya berdasarkan ajaran Islam.

Pengertian tersebut sejalan dengan pendapat Ny. Aisyah Dahlan bahwa pendidikan adalah membina pertumbuhan dan perkembangan anak untuk mencapai kedewasaan dalam artikata yang seluas-luasnya, baik rohani atau jasmani, serta memupuk kemampuan anak, baik mental, fisik, dan teknis untuk dapat berdiri sendirimenghadapitantangan-tantangan hidup. ${ }^{3}$

2. Beberapa Aliran dalam Pendidikan.

Anak didik harus mendapat pengajaran dan pendidikan dari para pendidik agar masa depannya tidak sesat. Menurut ajaran Islam, setiap anak dilahirkan dalam kondisi fitrah (suci bersih). Hal ini sesuai dengan hadits Nabi:

\footnotetext{
${ }^{2}$ Abdul Latif Mukhtar, Tujuan Pendidikan Islam dan Tujuan Pendidikan Nasional, (Cirebon : Panitia Seminar dan Lokakarya Nasional Ilmu Pendidikan Islam, 1995), h. 4

${ }^{3}$ Aisyah Dahlan, Prinsip-prinsip Pendidikan Agama Islam, (Surabaya : al-Ma'arif, 1968), h.9
} 


$$
\text { كل مولود يولد على الفطرة فابو اه يهودانه او ينصر انه او يمجسانه }
$$

Artinya:

Setiap anak yang dilahirkan adalah suci bersih. Bergantung kepada kedua orang tuanyalah ia (bisa) menjadi Yahudi, Nasrani, atau Majusi

Abdurrahman al-Bany mengemukakan langkah-langkah pendidikan; pertama, memelihara dan memperhatikan kesucian anak didik, kedua, menumbuhkan potensi dan kesiapan anak, ketiga, mengarahkan kesucian dan potensi yang ada pada anak didik untuk kebaikan dan kesempurnaan yang layak bagi anak; dan keempat, pelaksanaannya secara berangsur-angsur.

Dalam dunia pendidikan telah lama terjadi perdebatan tentang perkembangan manusia, apakah ditentukan oleh pembawaan ataukah oleh lingkungan?. Dalam hal ini terdapat beberapa aliran yang berusaha menjawab persoalan tersebut sebagai berikut:

\section{a. Aliran Nativisme}

Aliran ini berpendapat bahwa segala perkembangan manusia telah ditentukan oleh faktor-faktor yang dibawa sejak lahir. Pembawaan yang telah terdapat pada waktu dilahirkan itulah yang menentukan hasil perkembangannya. Menurut Nativisme, pendidikan tidak dapat mengubah sifat-sifat pembawaan. Andai kata benar pendapat tersebut, kiranya percuma saja pendidikan dilakukan, atau dengan kata lain, pendidikan tidak diperlukan. Pendapat ini dalam ilmu pendidikan disebut pesimisme pedagogis

b. Aliran Empirisme

Aliran ini mempunyai pendapat yang berlawanan dengan kaum Nativisme. Mereka berpendapat bahwa perkembangan anak menjadi manusia dewasa ditentukan oleh lingkungannnya atau pendidikan dan pengalaman yang diterimanya sejak kecil. Pendapat kaum Empirisme ini dikenal dengan nama optimisme pedagogis 
c. Aliran Konvergensi

Aliran konvergensi berasal dari ahli psikologi bangsa Jerman, William Stern. Ia berpendapat bahwa pembawaan dan lingkungan kedua-duanya menentukan perkembangan manusia. ${ }^{4}$ Menurut penulis, aliran konvergensi ini sejalan dengan ajaran Islam, sedangkan aliran Nativisme bertentangan dengan akal sehat. Buat apa Allah menurunkan al-Qur'an dan mengutus para Rasul ke dunia kalau manusia tidak bisa dibentuk karakternya, dan untuk apa pula pemerintah membangun sekolah dari tingkat dasar sampai perguruan tinggi, jika tidak ada gunanya. Menurut ajaran Islam, manusiaitu mempunyai dua potensi (jahat dan takwa atau positif). Hal ini dikemukakan dalam firman Allah:

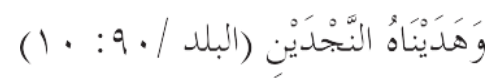

Artinya:

Dan kami telah menunjukkan kepadanya dua jalan [jalan kebajikan dan kejahatan

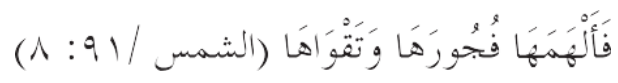

Artinya:

Maka Allah mengilhamkan kepada jiwa itu(jalan) kefasikan dan ketakwaannya.

Ajaran Islam mengakui adanya perbedaan bakat pembawaan pada diri seseorang, namun perbedaan tersebut bukan berarti tidak bisa dibentuk sama sekali. Sebagai contoh, seorang mahasiswi IIQ yang tidak mempunyai bakat nagam al-Qur'an, tetapi ia mempelajarinya untuk memperoleh juara Internasional tentu ia akan mengalami kesulitan, tetapi, barang kali, untuk juara tingkat RT atau RW ia akan berhasil, karena ia belajar nagam sedangkan yanglain tidak mempelajarinya.

Tujuan Allah menciptakan manusia tidak sama bakat dan pembawaannya agar terdapat saling ketergantungan satu

${ }^{4}$ M. Ngalim Purwanto, Psikologi Pendidikan, (Bandung: PT.Remaja Rosdakarya, 1953), h.14 
sama lain. Kalau manusia semua bisa melagukan al-Qur'an, tentu para qaridan qariah tidaklaku. Kalau semua manusia mempunyai bakat menjadi dokter, tentu para dokter tidak laku di masyarakat, begitu pula yang lainnya. Jadi manusia mempunyai kelebihan di satu bidang, tetapi juga mempunyai kelemahan dibidanglain. Halitu sesuai dengan petunjukalQur'an:

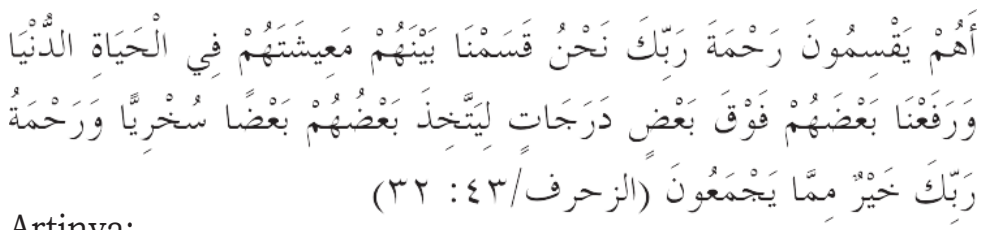

Artinya:

Apakah mereka yang membagi-bagi rahmat Tuhanmu? kami telah menentukan antara mereka penghidupan mereka dalam kehidupan dunia, dan kami telah meninggikan sebahagian mereka atas sebagian yang lain beberapa derajat, agar sebagian mereka dapat mempergunakan sebagian yang lain. Dan rahmat Tuhanmu lebih baik dari apa yang mereka kumpulkan.

\section{Penyesuaian Materi dan Masa Pendidikan}

Departemen Pendidikan dan Kebudayaan telah mengambil kebijakan link and match yang bertujuan untuk meningkatkan relevansi pendidikan dengan kebutuhan pembangunan pada umumnya dan kebutuhan dunia kerja, dunia usaha, dan dunia industri padakhususnya. ${ }^{5}$

Kebijaksanaan tersebut sesuai dengan ajaran Islam, sebagaimana diungkapkan oleh Ali bin Abi Talib:

$$
\text { علموا اولادكم فاهم مخلوقون لزمان غير زمانكم }
$$

Artinya:

Didiklah anak-anak mu, karena mereka diciptakan untuk zaman yang berbeda dengan zamanmu

\footnotetext{
${ }^{5}$ Wardiman Djoyonegoro, Arah dan Sasaran PJPT II Sepuluh Tahun Pertama Bidang Pendidikan (Pendidikan Tinggi), (Bogor: Panitia Seminar Nasional Kebijakan dan Strategi Pengembangan Perguruan Tinggi di Indonesia, 1993), h. 5
} 
Agar mencapai sasaran dan berhasil dengan baik, pendidikan perlu disesuaikan dengan perkembangan anak didik. Halini sesuai dengan hadits Nabi:

Artinya:

$$
\text { خاطبو ا الناس على قدر عقوهم }
$$

Berbicaralah kepada manusia sesuai dengan tingkat perkembangan akalnya

Masa pendidikan dalam Islam tidak dibatasi, tetapi dimulai sejak masih dalam buaian sampai keliang lahat (meninggal dunia). Hal ini diungkap dalam sebuah hadits Nabi :

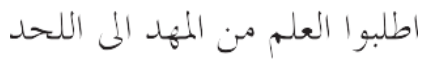

Artinya:

Tuntutlah ilmu sejak dari buaian hingga keliang lahat

\section{Pelaksanaan Pendidikan}

Jika ilmu pendidikan membahas pertumbuhan dan perkembangan manusia, al-Qur'an membahas pendidikan segala yang ada, termasuk pendidikan manusia. Kata rabbil 'alamin dalam surat al-Fatihah mempunyai arti Murabbi al'alamin (pendidik semesta alam). Dengan demikian, Allah SWT adalah pendidik Yang Maha Besar di dalam alam semesta ini. ${ }^{6}$

Allah menciptakan manusia di alam ini, menurut alQur'an, sebagai khalifah (pengganti)-Nya. Artinya bahwa manusia telah menerima amanah Allah yang akan diminta pertanggungjawabannya oleh Allah di akhirat kelak. Oleh karena itu, setiap manusia harus dapat memakmurkan dan melestarikan alam dunia ini. Sebab, manusia semuanya adalah murabbi (pemelihara dan pendidik). Hal ini sebagaimana diungkapkan dalam firman Allah :

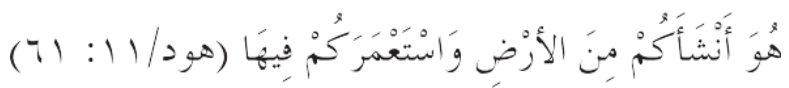

\footnotetext{
h. 10

${ }^{6}$ Muhammad Fadlila Jamali, Konsep Pendidikan al-Qur'an, (Solo: Ramadhani, t.t.),
} 
Artinya:

Dia telah menciptakan kamu dari bumi (tanah) dan menjadikan kamu pemakmurnya

Untuk itu, Rasulullah menganjurkan kepada semua manusia agar menyampaikan (mengajarkan) apa yang disampaikan beliau walaupun satu ayat. Hal ini ditegaskan dalam sabdanya:

Artinya:

$$
\text { بلغواعنى ولو اية }
$$

Sampaikanlah, wahai manusia, dariku walau satu ayat

Berdasarkan hadits di atas, jelaslah bahwa tanggung jawab pendidikan tidak terbatas pada guru sekolah atau para kyai di pesantren, tetapi pada semua pihak, keluarga, masyarakat (lingkungan) dan pemerintah, bahkan seluruh individu manusia.

\section{Masa Kematangan Belajar}

Kematangan yang dimaksud adalah kematangan potensi fisik dan mental psikologis yang telah dicapai dalam satu tahap pertumbuhan atau perkembangan. Menurut para pakar psikologi, perkembangan otak anak untuk menerima pengetahuan akademik di sekolah adalah ketika ia berusia tujuh tahun.

Masa kematangan belajar telah diungkap Rasulullah sebelum para pakar psikologi mengungkapkannya. Hal ini tercermin dalam hadits :

$$
\begin{aligned}
& \text { مرو ا اولادكم بالصلاة وهم ابناء سبع سنين و اضر بوهم عليها وهم ابناء عشر } \\
& \text { وفرقوهم فن المضاجع (رواه ابو داودد) }
\end{aligned}
$$

Artinya:

Perintahkan anak-anakmu untuk sholat ketika mereka berusia tujuh tahun, pukulah mereka bila tidak mengerjakan sholat ketika berusia sepuluh tahun dan pisahkan mereka (dari mu) dalam tempat tidur mereka (HR. Abu Daud). 
Dari hadits di atas dapat dipahami bahwa manusia itu mempunyai tahapan-tahaapan belajar, mulai tahap SD berusia tujuh tahun dan SMP berkisar usia 10 atau 11 tahun.

Adanya batas kematangan usia untuk belajar, sebagaimana dikemukakan di atas, bukan berarti anak di bawah usia tersebut tidak boleh belajar. Karena dalam Islam belajar dimulai sejak lahir sampai meninggal dunia. Hanya saja, perlu diperhatikan tahapan-tahapan usia belajar. Hal ini tercermin dalam hadits Nabi SAW:

$$
\text { خاطبو الناس على قدر عقولمم }
$$

Artinya:

Berbicaralah kepadamanusiasesuaidenagantingkat perkembangan akalnya

Sejalan dengan hadits di atas, salah seorang tokoh pendidik (Comenius) membagi macam-macam sekolah disesuaikan dengan perkembangan anak, yaitu:

a. Masa sekolahibu, untuk anak-anakumur 0,0-6,0 tahun

b. Masa sekolah bahasa ibu, untuk anak-anak umur 6,0-12,0 tahun

c. Masa sekolah bahasa latin, untuk anak-anak umur 12,0-18,0 tahun

d. Masa sekolah tinggi, untuk anak-anakumur 18,0-24,0 tahun

\section{Kedudukan dan Ciri Orang Berilmu}

Kualitas manusia berilmu tentu berbeda dengan manusia yang tidak berilmu. Hal ini diungkap dalam firman Allah:

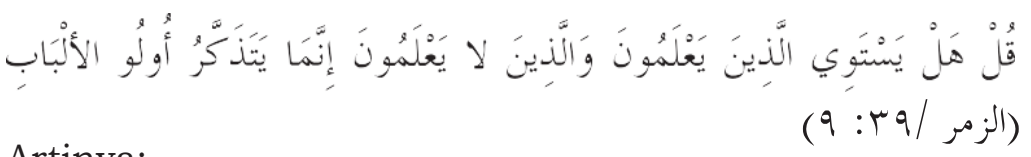

Artinya:

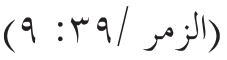

Katakanlah: "Adakah sama orang-orang yang mengetahui dengan 
orang-orang yang tidak mengetahui?" Sesungguhnya orang yang berakallah yang dapat menerima pelajaran.

Dalam ayat lain dijelaskan bahwa Allah akan mengangkat orang berilmu yang beriman beberapa derajat. Hal ini diungkapkan dalam firmannya :

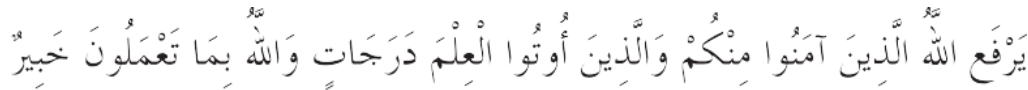

Artinya:

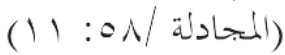

Allah akan meninggikan orang-orang yang beriman di antaramu dan orang-orang yang diberi ilmu pengetahuan beberapa derajat. dan Allah Maha mengetahui apa yang kamu kerjakan.

Adapun ciri-ciri orang berilmu, menurut al-Qur'an adalah zikir dan pikir sebagaimana ditegaskan Allah dalam firman-Nya:

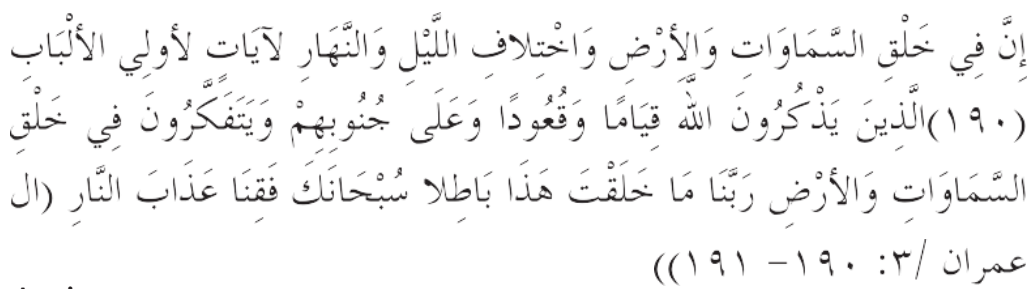

Artinya:

Sesungguhnya dalam penciptaan langit dan bumi, dan silih bergantinya malam dan siang terdapat tanda-tanda bagi orangorang yang berakal, (yaitu) orang-orang yang mengingat Allah sambil berdiri atau duduk atau dalam keadan berbaring dan mereka memikirkan tentang penciptaan langit dan bumi (seraya berkata): "Ya Tuhan kami, tiadalah Engkau menciptakan Ini dengan sia-sia, Maha Suci Engkau, Maka peliharalah kami dari siksa neraka".

Artinya orang intelektual itu saratnya selalu ingat pada Allah dan mau meneliti dan mengamalkan ilmunya sehingga menjadi orang yang taqwa. Dan orang yang taqwa, Allah akan memberikan ilmu: 


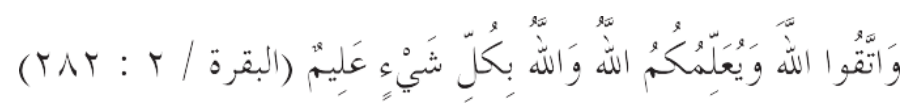

Mengapa orang Islam tidak dapat menemukan teknologi? Karena taqwanya baru separoh. Dan ilmu yang dimaksud bukan hanya ilmu agama melainkan ilmu-ilmu lain yang menjadikan seseorang itu takut melanggar ajaran Allah yang pada gilirannya mendorong orang yang berilmu itu untuk mengamalkan ilmunya serta memanfaatkannya untuk kepentingan makhluk Allah sebagaimana yang ditegaskan Allah :

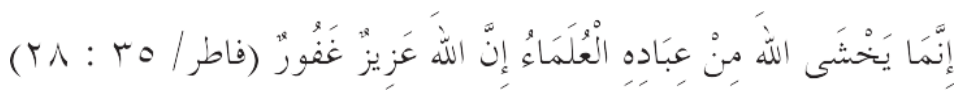

Oleh karena itu Nabi selalu berdoa agar ilmunya selalu bermanfaat :

$$
\text { اللهم الن اعوذبك من علم لا ينفع }
$$

Artinya:

Ya Allah sesungguhnya aku berlindung kepada-Mu dari ilmu yang tidak bermanfaat

Karena orang yang tidak mengamalkan ilmunya dianggap tidak kritis, padahal orang berilmu itu harus kritis, sebagaimana ditegaskan Allah:

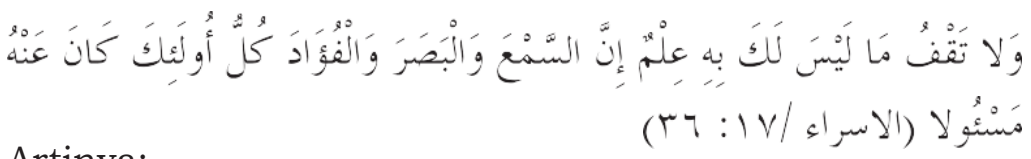

Artinya:

Dan janganlah kamu mengikuti apa yang kamu tidak mempunyai pengetahuan tentangnya. Sesungguhnya pendengaran, penglihatan dan hati, semuanya itu akan diminta pertanggungan jawabnya.

Di samping orang berilmu harus kritis juga harus konsisten (istiqamah), artinya seorang yang berilmu harus mempertahankan kebenaran sampai meninggal dunia kecuali dalam keadaan darurat. Sebab orang yang berfatwa tetapi tidak melaksanakan apa yang difatwakannya, akan diancam atau dibenci Allah. Hal ini diungkap dalam firman Allah: 


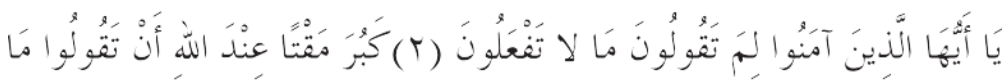

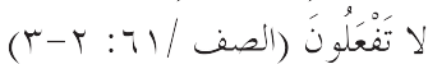

Artinya:

Wahai orang-orang yang beriman, kenapakah kamu mengatakan sesuatu yang tidak kamu kerjakan? Amat besar kebencian di sisi Allah bahwa kamu mengatakan apa-apa yang tidak kamu kerjakan.

Orangyang konsisten akan dijanjikan Allah akan mendapat surga diakhirat nanti. Sebagaimana ditegaskan Allah:

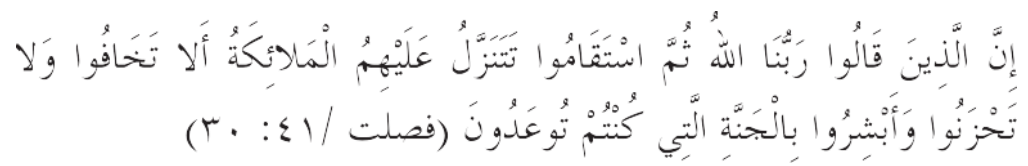

Artinya:

Sesungguhnya orang-orang yang mengatakan: "Tuhan kami ialah Allah" Kemudian mereka meneguhkan pendirian mereka, Maka malaikatakanturunkepadamerekadenganmengatakan:"Janganlah kamu takut dan janganlahmerasa sedih; dan gembirakanlah mereka dengan jannah yang telah dijanjikan Allah kepadamu".

\section{Hubungan antara Pendidikan dan Islam}

Islam adalah syari'at Allah untuk manusia agar mereka dapat menjalankan amanah-Nya, sesuai dengan firman-Nya:

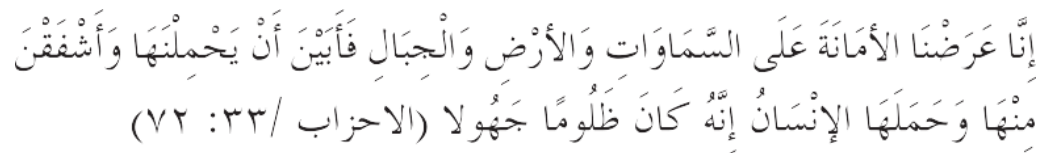
Artinya:

Sesungguhnya kami telah mengemukakan amanat kepada langit, bumi dan gunung-gunung, maka semuanya enggan untuk memikul amanat itu dan mereka khawatir akan mengkhianatinya, dan dipikullah amanat itu oleh manusia. Sesungguhnya manusia itu amat zalim dan amat bodoh. 
Pendidikan adalah menumbuhkan pikiran dan mengatur tingkah laku dan perangai manusia. Antara pendidikan dan Islam tidak dapat dipisahkan, bahkan saling mengisi. Allah SWT menilai orang sepandai apapun bila tidak beribadah kepadaNya tidak dikatakan orang berilmu, bahkan lebih rendah dari binatang.

Nabi Adam sebelum diutus oleh Allah kepada umat manusia dididiklebih dahulu. Halini tercermin dalam firman Allah:

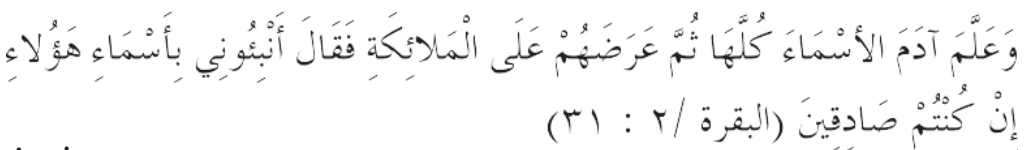

Artinya:

Dan dia mengajarkan kepada Adam nama-nama (benda-benda) seluruhnya, Kemudian mengemukakannya kepada para malaikat lalu berfirman: "Sebutkanlah kepada-Ku nama benda-benda itujika kamu mamang benar orang-orang yang benar!"

Amanah yang diberikan oleh Allah kepada manusia baru dapat terlaksana bila ia memiliki ilmu. Selain itu, Allah menciptakan manusia adalah untuk beribadah kepada-Nya. Karena itu, pendidikan sebagai bagian dari ibadah kepada Allah tidak boleh bebas nilai, tetapi harus dilandasi nilai-nilai Islam. Sebagaimana ditegaskan Allah:



Artinya:

Dan Aku tidak menciptakan jin dan manusia melainkan supaya mereka mengabdi kepada-Ku.

\section{PENUTUP}

Pendidikan dalam pandangan Islam merupakan salah satu bentuk pengabdian kepada Allah dan faktor utama bagi manusia untuk mengemban tugas kekhalifahannya di bumi. Pendidikan 
dalam pengertian tarbiyah dan ta'lim sangat penting dalam rangka mencerdaskan akal sekaligus membentuk mental kejiwaan peserta didik.

Demi mencapai tujuan tersebut, Islam tidak memisahkan ilmu dan amal, sehingga pendidikan tidak netral atau bebas nilai, tapi justru harus dilandasi nilai-nilai moral Islam. Dengan kata lain, Islam memandang perlunya "keberpihakan" pendidikan kepada misi diciptakannya manusia di dunia, yakni pengabdian kepada Allah dan memegang amanat kekhalifaan di bumi. Hal tersebut harus dimulai sedini mungkin sehingga nilai-nilai Islam tertanam kokoh dalam akal dan jiwa.[]

\section{DAFTAR REFERENSI}

Dahlan, Aisyah, Prinsip-prinsip Pendidikan Agama Islam, Surabaya: al-Ma'arif, 1968

Djoyonegoro, Wardiman, Arah dan Sasaran PJPT II Sepuluh Tahun Pertama Bidang Pendidikan (Pendidikan Tinggi), Bogor: Panitia Seminar Nasional Kebijakan dan Strategi Pengembangan Perguruan Tinggi di Indonesia, 1993

Jamali, Muhammad Fadlila, Konsep Pendidikan al-Qur'an, Solo: Ramadhani, t.t.

Mukhtar, Abdul Latif, Tujuan Pendidikan Islamdan Tujuan Pendidikan Nasional, Cirebon : Panitia Seminar dan Lokakarya Nasional Ilmu Pendidikan Islam, 1995

Purwanto, M. Ngalim, Psikologi Pendidikan, Bandung: PT.Remaja Rosdakarya, 1953

Toha, M. Chabib, Strategi Pendidikan Islam Menyongsong Abad XXI, Cirebon : Panitia Seminar dalam Lokakarya Nasional Pendidikan Islam, 1995 
H. Anshori

176 HIKMAH, Vol. XIII, No. 2,2017 